\title{
O humano, o pastorado e a psicologia ${ }^{\star}$
}

\author{
Sandra Raquel Santos de Oliveira ${ }^{\text {Orcid, } \star \star}$ \\ Universidade Federal Fluminense, Niterói, RJ, Brasil
}

\begin{abstract}
Resumo
Este trabalho parte de uma dúvida lançada por Foucault acerca do fim da era pastoral, tentando destacar os possíveis pontos de convergência entre algumas práticas da Psicologia em diferentes contextos institucionais e o pastorado, enquanto dispositivo de poder. Nesse percurso, tentamos dar ênfase ao que consideramos os efeitos desses pontos de convergência: a produção de uma humanidade associada ao caráter dócil. Essa análise direciona-se, principalmente, para os processos de subjetivação essencializados, unificados, interiorizados e bem delimitados como efeitos de exercícios de poder-saber no campo do que se convencionou chamar de ciência psicológica e seus atravessamentos com as perspectivas de garantias de direitos universais. Em linhas gerais, a questão que se coloca para as práticas psi é em que medida elas colaboram na naturalização da servidão e de condutas pacificadas como eminentemente humanas, configurando-se como uma nova modalidade de poder pastoral, ou nos dizeres de Foucault, como uma modalidade de pastorado laico.
\end{abstract}

Palavras-chave: psicologia; pastorado; governo.

\section{Human, pastorate and psychology}

\section{Abstract}

This work starts from a doubt thrown by Foucault about the end of the pastoral era, trying to highlight the possible convergence points among some practices of the Psychology in different institutional contexts and the pastorate, while power tool. In that course, we tried to give emphasis to that we considered the effects of those convergence points: a production of a humanity associated to the docile character. That analysis is addressed, mainly, for the subjectivation processes essentialized, unified, internalized and well delimited as effects of exercises of power-knowing in the field of what it is stipulated to call psychological science and their crossings with the perspectives of warranties of universal rights. In general lines, the question that it is put for the psi practices is in which measure they collaborate in the naturalization of the servitude and of conducts pacified as eminently human, being configured as a new modality of pastoral power, or as Foucault says, as a modality of a laic pastorate.

Keywords: psychology; pastorate; government.

E, quando eu me coloco no século XVIII como sendo o fim da era pastoral, é provável que ainda me engane, porque de fato o poder pastoral em sua tipologia, em sua organização, em seu modo de funcionamento, o poder pastoral que se exerceu como poder é sem dúvida algo de que ainda não nos libertamos (FOUCAULT, 2008, p. 197).

Essa questão colocada por Michel Foucault serve-nos como ponto de partida para pensar de que maneira e a partir de quais estratégias o poder pastoral se exerce na contemporaneidade. Seguiremos os apontamentos desse autor em torno de suas transformações e atualizações históricas para elaborar nossa proposta de articulação entre esse modo de exercício de poder e as práticas da Psicologia. Destacamos, em primeiro lugar, como pressuposto básico desse trabalho a perspectiva foucaultiana de pensar o sujeito como um efeito de determinadas práticas sociais.

Desdobramos desse pressuposto nossas propostas de trabalho: pensar de que maneira as práticas da psicologia articulando-se ao funcionamento disciplinar das relações de poder e ao dispositivo de segurança na produção da subjetividade considerada moderna - especialmente na faceta da sua composição com a noção de sujeito livre e de direito - destacam-se, do seu lugar de falas com-

^O artigo é parte de uma pesquisa de doutorado em Psicologia financiada pela Coordenação de Aperfeiçoamento de Pessoal de Nível Superior (CAPES) e que segue no Programa Nacional de Pós-Graduação da CAPES (PNPD).

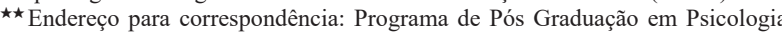
da Universidade Federal de Sergipe, Cidade Universitária Prof. Aloísio de Campos, Av. Marechal Rondon, S/N, Jardim Rosa Elze, CEP: 49.100.000, São Cristóvão. E-mail: sraquel.oliveira31@gmail.com petentes, ${ }^{1}$ como discursos produtores de docilidade e obediência. Para tal, e em relação a esse desdobramento, propomos pensar a Psicologia ${ }^{2}$ como parte importante na e da criação de uma cultura de valorização da servidão como característica eminentemente humana. Por que a Psicologia? Tomaremos como prática privilegiada - em relação apenas a nossa análise, - as práticas psi. Entendemos que o chamamos de produção de obediência na qual estão envolvidas as práticas dos psicólogos não é uma exclusividade deste campo de práticas e de produção de saber, mas a atravessa, e, portanto, nos atravessa.

Tomemos aqui o que seria um segundo pressuposto deste trabalho: Frequentemente, nos deparamos com perspectivas que se consideram críticas a respeito do tema relacionado aos assim chamados Direitos ${ }^{3}$ Humanos que colocam a seguinte questão, formulada dos mais

${ }^{1} \mathrm{O}$ destaque à expressão "competência" é dado por Chauí (1982) e utilizado por Coimbra (2002) para discutir a pretensa neutralidade e cientificidade das falas dos especialistas, problematizando especialmente os psis, tomados como nosso campo de análise. Esses discursos, tomados como tais, além de opera uma dicotomia entre Psicologia e Política, "[...] geram o sentimento coletivo de incompetência, poderosa arma de dominação, pois serão elas que dirão, em última instância, a todos como 'ver, tocar, sentir, falar, ouvir, escrever, ler, pensar e viver"' (CHAUÍ, 1982, p. 59 apud COIMBRA, 2002, p. 8, grifo do autor).

${ }^{2}$ Como bem observa Abreu (1991), pensando no caso das práticas psicanalíticas, que ela problematiza no seu trabalho como práticas que repetem o modelo médico de saber-poder. Trata-se de práticas reguladas pelas lógicas de adaptação e da psiquiatria, integrando-se em parcelas significativas dos meios de controle social. ${ }^{3}$ Ressaltamos que não estamos usando nossa pesquisa como um clamor pela garantia de direitos. Entendemos o Direito produzido como um valor e um ideal a ser sempre alcançado e garantido, localizado em nossa sociedade somente a partir das reverberações dos ideais da Revolução Francesa, operando, talvez, como um sintoma de uma sociedade desigual e injusta. Entretanto, e por isso mesmo, tende a permanecer sempre no campo da transcendência, apesar das lutas. Não se pretende ainda descartar seu uso como modo de fortalecimento de lutas, apenas evitar a naturalização do mesmo. 
variados modos: Direitos Humanos para quem? Nossa questão está mais atenta a como se produz esse "quem": quais condutas passaram a ser valorizadas como tipicamente humanas? Em quais circunscrições sociais/econômicas/geográficas esses modos de subjetivação hegemônicos estariam situados? Quais condutas passam a ser consideradas inumanas a partir de uma Declaração que se pretende Universal? Quais "tipos"4 estariam cobertos por essa pretensa universalidade? E a mais importante - e que, talvez, mais implica nas práticas psi - Como se produz essa noção de humano?

Ocupamo-nos, pois, num breve exercício de análise de implicação, acerca de como a Psicologia se articula nessas definições, de que modo ela legitima, com suas verdades sobre os sujeitos, os processos históricos de exclusão social associada à produção de violência institucional ${ }^{5}$ produzida pelo Estado capitalista ao tempo em que reafirmamos a aposta nas possibilidades de produção de práticas outras.

Pretendemos colocar em análise, portanto, o próprio conceito de humano que emerge a partir da invenção desses direitos universais. Entendemos que essa problematização passa pela reativação do campo dos Direitos Humanos como um campo de lutas. Coimbra, Lobo e Nascimento (2009) nos lembram de que não raramente tomamos esses direitos como frutos de uma espécie de evolução que se dirigiria a um progresso do chamado gênero humano, que, por sua vez, o aproximaria do que seria o homem civilizado. Para essas pesquisadoras, essa concepção não somente cria um artifício de um marco histórico que tenha efetivamente inaugurado novas práticas para os direitos (como se alguns problemas tivessem deixado de existir), como traz consigo alguns termos, que, de tanto serem evidenciados e repetidos, passam a ser percebidos como um a priori, tais quais as palavras de ordem da Revolução Francesa - liberdade, igualdade e fraternidade.

Produzidos pelo capitalismo como um dado natural, tornaram-se, portanto, sinônimos de direitos inalienáveis da essência do que é ser homem. Tem-se, então, um determinado 'rosto' para os direitos humanos desde a primeira grande declaração produzida num âmbito da luta realizada pela burguesia contra a aristocracia francesa, em 1789, até a mais recente declaração de 1948 (COIMBRA; LOBO; NASCIMENTO, 2009, p. 33).

Estamos investindo, portanto, na espreita de como as construções em torno da noção de sujeito podem contribuir na compreensão de funcionamentos e organizações sociais que operam práticas de normalização e homoge-

\footnotetext{
"“Tipo" aqui se justifica por entender que essas produções hegemônicas que fazem emergir um humano universalizado, tomando-o como dotado de um padrão de comportamento, que reúne "traços" específicos, compondo um "tipo", que representa uma espécie de regularidade de conduta, como descrito nos grandes manuais de Psicologia da Personalidade.

${ }^{5}$ Expressão de Mendonça Filho (2009), que marca uma posição política frente à possibilidade de se lidar com a noção de violência substancializada - A Violência. Contrariando uma perspectiva que parte de categorias universais, o termo violência pode ser associado a um excesso, mas os excessos não possuem uma natureza em comum. No caso da 'Violência Institucional', sua produção e reprodução estão associadas à manutenção do controle das relações cotidianas, apartado de qualquer compromisso com a vida, pelo modo de funcionamento do modelo de Estado do capitalismo financeiro.
}

neização que tendem à dominação e exclusão, atualmente, em nome de uma série de dispositivos chamados de segurança, de proteção e de inclusão social.

Nos percursos dessa pesquisa, cruzamos com a noção de Direito de Guerra, definido como o direito de não ser governado por um igual - pautada por Espinosa (2009) em seu Tratado Político e discutida por Laurent Bove (2010). Propomos uma pequena articulação nesse trabalho, ainda que parcial e pontual, com essa noção, pois ela nos fez pensar em um adendo daquele sujeito moderno que já nos referimos - o sujeito de vontade, livre, autônomo e de direito. Faltava acentuar-lhe uma característica indispensável à composição do sujeito considerado civilizado: ser pacífico. Ora, se a Psicologia em questão é moderna, podemos pensar que os ideais da Revolução Francesa constituem seu suposto objeto. Pensando o Direito de Guerra como estando em oposição à servidão podemos afirmar que na contemporaneidade tem se valorizado cada vez mais o ideal de fraternidade, equivalendo-o à servidão ou obediência. Dizendo de outro modo, parece que o que se considera como humano é cada vez mais equivalente a dócil.

Nesse sentido, de acordo com Coimbra, Lobo e Nascimento (2009), o lema da fraternidade compõe historicamente com estratégias como a caridade religiosa, a chamada filantropia científica e com o assistencialismo de Estado. Para elas, os processos de subjetivação produzidos aí estão sempre no território da falta, do fortalecimento de valores morais que comporiam os chamados cidadãos de bem. "O que isso traz? A manutenção da miséria, o apaziguamento das rebeldias, quando não a figura da vítima" (COIMBRA; LOBO; NASCIMENTO, 2009, p. 34). De maneira sucinta, nossos principais temas de análise estão delineados aqui: os discursos constituintes de um “tipo" humano e as práticas psi articuladas à produção de uma subjetividade interiorizada, pacificada e obediente.

Dito isso e pensado numa análise dos efeitos das práticas psi, problematizamos a produção de subjetividade historicamente articulada à valorização da noção de uma interioridade psíquica e do enfraquecimento da perspectiva de modos de subjetivação em sua dimensão coletiva, engendrada numa prática social que se constituiu como plano comum de ações políticas coletivas, na esteira de um mesmo movimento de despotencialização, através de estratégias de gestão dos espaços públicos.

Nesse ponto, destacamos o problema do governo e de sua articulação com as práticas psi nesse empreendimento eminentemente moderno. Nesse sentido, trata-se de pensar a produção de corpos obedientes como efeito de práticas de ortopedia moral diversas, mas concêntricas que criam como critério o humano atrelado à docilidade e seus correlatos. Problematiza-se, nesse sentido, o ideal de neutralidade no qual se apoia esses discursos competentes, como tendo o propósito de esfumaçar seus atravessamentos pelos valores morais do mundo moderno/ capitalista e por um modo de organização política que opera uma padronização unificadora como o Estado. Pode-se desse modo, colocar em análise como, em nome dos discursos de humanização, que aparecem articulados 
a uma nova economia da punição e de controle, desenvolvem-se estratégias diferenciadas do que Foucault (2008) chamou de governo das condutas.

\section{O Pastorado e a Atividade Política}

Foucault (2008) elabora uma breve, mas complexa discussão para apoiar sua tese de que a história do pastorado no mundo ocidental só começa com o cristianismo. Essa discussão passa essencialmente pela diferenciação entre o pastor e o homem político na Antiguidade. De acordo com ele, a política não deve se ocupar globalmente de tudo, tal como o pastor deveria cuidar do seu rebanho. Por outro lado, e talvez por isso mesmo, a ação política depende de ações adjuvantes e preparatórias atividades menores, mas necessárias à cidade e subordinadas à ação política. Como exemplos, ele nos traz a ação do médico, do agricultor, do ginasta e do pedagogo (podemos incluir aqui a aplicação dessa metáfora às práticas psi), essas sim, podendo ser consideradas pastorais; mas o homem político não é um pastor. O homem político domina a arte de prescrever, de comandar. A reflexão grega sobre política exclui, portanto, de acordo com esse autor, a valorização do tema do pastor.

Esse poder globalmente pastoral permaneceu, ao longo do cristianismo chamado de arcaico, distinto do poder político. Isso não quer dizer que o poder religioso nunca tenha se dado como tarefa outra coisa, senão encarregar-se das almas dos indivíduos. Ao contrário, para Foucault (2008), o poder pastoral - é essa uma de suas características fundamentais - só se encarrega da alma dos indivíduos na medida em que essa condução das almas implica também uma intervenção permanente na condução cotidiana, na gestão das vidas, nos bens, nas riquezas, nas coisas; ou seja, em uma produção de um certo modo de existir. É, portanto, uma forma de poder terrestre, apesar de ter, por fim, o além. $O$ entrecruzamento do poder pastoral e do poder político será efetivamente uma realidade histórica no Ocidente e conservará características próprias. Entretanto, para esse autor, o poder pastoral continuará específico e diferente do poder político, ainda que a Igreja e o Estado tivessem todas as formas de alianças.

Mas, qual seria a importância de discutir aqui essa especificidade do poder pastoral? Tomemos como motivo um dos objetivos apontados por Foucault (2008): o de mostrar que a moral judaico-cristã não existe; no sentido de que não é natural. Ela só pode ser concebida como artifício. E que se há alguma relação entre religião e política, essa relação talvez passe mais pelo jogo entre pastorado e governo do que entre Igreja e Estado. Destacamos ainda a importância de desnaturalizar não somente a moral judaico-cristã, mas todos os seus elementos presentes nas produções de subjetividade contemporânea e frequentemente legitimados pelas práticas psi como naturalmente e saudavelmente humanos. Podemos destacar aqui a obediência como virtude no campo da moral cristã e como sinal de saúde no campo das práticas de medicalização da vida e de governo das condutas.

Fractal, Rev. Psicol., v. 30 - n. 1, p. 39-45, 2018
Há ainda uma transição/atualização do modo de funcionamento do poder pastoral que interessa em demasia ao nosso trabalho - já que pretendemos pensar nas atualizações de elementos do pastorado em práticas emergentes na modernidade - assinalada por Foucault (2008): como muitas das funções pastorais são retomadas no exercício da governamentalidade entre os séculos XVII e XVIII, na medida em que o governo pôs-se também a querer se encarregar da conduta dos homens. Os problemas dos conflitos de conduta vão passar a ser muito mais uma questão para as instituições políticas do que para as religiosas. É aqui que entendemos entrar o papel das práticas psi. Ora, como todos sabemos, a Psicologia emerge como uma promessa no campo das Ciências, pós-revolução burguesa, imersa no contexto dos ideais liberais, humanistas, iluministas, românticos... Não poderia ser, obviamente, um braço das instituições religiosas. Mas, se estamos percorrendo caminhos que pensam a história como nos propõe Foucault, ${ }^{6}$ estamos pondo em análise como no seio de uma chamada "Revolução Científica", que prometia subverter qualquer possibilidade de relação dogmática na produção de saber, resistem e transmutam-se focos de dogmatismo, obscurantismo e práticas psi tão fartamente encharcadas de moralismos religiosos. Dizendo de outro modo: como o pastorado transforma-se para se tornar uma estratégia de governo das condutas no campo político com o aparecimento da forma Estado, articulado às falas competentes enunciadas pelos novos mandatários do governo das "almas"?

Importa-nos, ainda, destacar que Foucault (2013) enfatiza algumas mudanças importantes para pensarmos em termos de atualização e não de permanência do "mesmo" poder ao longo do tempo. Em primeiro lugar, acentua uma mudança no objetivo mencionado há pouco: já não se trata mais de dirigir o povo para a sua salvação no outro mundo, mas, antes, assegurá-la neste mundo. E o que significa isso nesse contexto? Ele nos mostra que a palavra salvação pode ter diversos significados: saúde, bem-estar (isto é, riqueza suficiente, padrão de vida), segurança, ${ }^{7}$ proteção contra acidentes. Ou seja, uma série de objetivos "mundanos" que derivaram dos objetivos da pastoral tradicional.

\footnotetext{
${ }^{6}$ Ver como Veyne (1998) toma a questão da história em Foucault: trata-se de um elemento inventivo, que reconfigura toda uma relação com a verdade. Destacamos, portanto, que quando nos referimos à história, estamos marcando uma ruptura com a História enquanto registro historiográfico e que supõe despretensiosamente narrar de maneira mais verídica um fato ocorrido. Pensamos história como mais uma prática discursiva que opera uma construção política de mundo.

O professor Frédéric Gros (2012) propõe pensar a Segurança como um Princípio balizador das sociedades contemporâneas. De acordo com ele, há uma queixa generalizada acerca de um agravamento do sentimento de insegurança e se anuncia, frequentemente, através de falas competentes (tradução livre minha para uma expressão literal "enunciados eruditamente") que a segurança é a liberdade primeira. Nota-se um grande fortalecimento das vozes que constituem a segurança, como o desemprego e a ecologia, uma preocupação majoritária da população, de fato, como uma condição indispensável ao desenvolvimento das crianças e autossatisfação do adulto, de acordo com ele. Ele desenvolveu, ainda, uma tese sobre o Princípio de Segurança, percorrendo as possibilidades de sentido que essa noção comporta e vai ganhando ao longo da história, o que nos auxilia a situar a que estamos nos referindo quando se fala em "Segurança": a segurança como "sensação de segurança"; como "estado de espírito"; segurança como ausência de perigo; a segurança como garantia do Estado, elemento de ordem pública material, caracterizada pela ausência de perigo para a vida, a liberdade ou o direito de propriedade privada. Por fim, a biosegurança, mais recente modalidade que visa garantir o funcionamento normal de uma atividade; o desenvolvimento normal de um processo; diz respeito à proteção, controle e regulação dos processos em geral.
} 
Vemos, portanto, que uma certa produção de bem-estar ${ }^{8}$ tornou-se objeto do poder pastoral moderno. Trouxemos os elementos dessa pastoral contemporânea que torna a salvação como um imperativo de felicidade nesse mundo, mas também alguns elementos daquela "pré-Estado" porque entendemos que ela não foi completamente abandonada, apenas passaram por uma espécie de transição. E quais seriam, então, os efeitos dessa transição?

[...] de fazer nascer uma nova ordem social, de suscitar um novo homem. E, por conseguinte, ele tem que necessariamente de funcionar, até certo ponto, como uma contra-sociedade, uma outra sociedade, mesmo que não faça mais que reproduzir a que existe; e, por conseguinte, ele se apresenta, ele funciona internamente como uma espécie de outro pastorado, de uma governamentalidade, com seus líderes, com suas regras, sua moral, seus princípios de obediência, e nessa medida, ele detém, como vocês sabem, uma enorme força para se apresentar ao mesmo tempo como uma outra sociedade, uma outra forma de conduta, e para canalizar as revoltas de conduta, para tomar o lugar delas e dirigi-las (FOUCAULT, 2008, p. 263).

Ora, o problema da viabilidade do governo, parece colocar o problema da intervenção em níveis de produção de modos de existir compatíveis com essas estratégias de poder. Como nos mostra esse autor, trata-se de operar um poder que age sobre a possibilidade de agir.

Pensamos em duas vias, que são complementares de uma mesma, dentre muitas possíveis, da inserção das práticas psi na articulação acima citada: surge como uma demanda do aparecimento da sociedade capitalista para legitimar os modos de existir individualizados e docilizados como dominantes, portanto, os mais próximos do que seria considerado como normal e saudável, mas também como produtora ativa de tal modo de subjetivação, tal como o experimentamos. Podemos supor, suposição sobre a qual se apoia essa pesquisa, que os processos de individualização são condição sem a qual não se pode produzir algo como a obediência. Ora, todo exercício de controle precisa, de algum modo, operar estratégias de fragilização daquilo que se pretende controlar. Podemos pensar os processos de individualização - sendo efeito das estratégias de disciplinarização - como fragilização do homem enquanto sujeito social, enquanto pertencente a uma rede; enquanto um agente político.

\section{O Pastorado e a Liberdade}

Um elemento fartamente destacado por Foucault (2008, p. 287) do poder pastoral é que seu modo de funcionar se apoia na estratégia de condução, destacando uma distinção entre violência e poder. Apesar de as relações de poder não dispensar o uso da violência, e recorrerem a ela com frequência, o autor enfatiza um instrumento/efeito das relações de poder que nos interessa particularmente: "a aquisição de consentimentos". Talvez esses sejam efeitos da ação do poder que estejam diretamente relacionados à produção do artifício da liberdade, do mito da liberdade individual. No limite, a possibilidade de ação

\footnotetext{
${ }^{8}$ Vide os produtos vendidos (sucesso profissional, saúde física e mental, relações amorosas satisfatórias, ausência de dor e sofrimento) pelas novas igrejasempresas que não param de se multiplicar no Brasil, especialmente nos territórios urbanos e rurais carentes de infraestrutura e serviços públicos mínimos.
}

do sujeito está garantida nas relações de poder e estas ainda produzem um consentimento desses sujeitos. Ao tempo que aniquila a vontade própria, faz acoplar com uma vontade outra a ponto de assumi-la como sua e atuar no mundo a partir dela. Perfeitos homens livres. O exercício de poder pode suscitar tanta aceitação quanto se queira:

Ele é um conjunto de ações sobre ações possíveis, ele opera sobre o campo de possibilidade onde se inscreve o comportamento dos sujeitos ativos; ele incita, induz, desvia, facilita ou torna mais difícil, amplia ou limita, torna mais ou menos provável; no limite ele coage ou impede absolutamente, mas é sempre uma maneira de agir sobre um ou vários sujeitos ativos, e o quanto eles agem ou são suscetíveis de agir. Uma ação sobre ações (FOUCAULT, 2013, p. 288).

Trata-se, como podemos ver no contexto do pastorado, de uma condução. Importante essa distinção colocada pelo autor, destacando que uma relação de violência age sobre um corpo, sobre as coisas, forçando, submetendo, destruindo e, produzindo, em outro polo, a passividade e reduzindo, ao máximo possível, a resistência. Enquanto que uma relação de poder se apoia necessariamente em um "outro" (aquele sobre o qual ela se exerce) que é o sujeito de ação. Ora, se é sobre a ação que o poder se exerce, é necessário preservar infinitamente o sujeito como sujeito de ação.

Talvez essa compreensão das relações de poder auxilie na problematização de uma suposta passividade ou apatia quando se trata de um engajamento no cenário político do Brasil na atualidade. É possível que tenhamos numerosos espaços que seriam, por excelência de ação política, como sindicatos, movimentos sociais, conselhos de fiscalização de gestão pública etc. Enfim, espaços de luta, de conquistas de direito, de organização de ações, mas demasiados protocolares e endurecidos, ou seja, estatais. Apesar de toda a importância histórica, dos espaços que abriram, lutas e sua reconhecida efetividade em vários aspectos, eles frequentemente cooptam as forças efetivamente questionadoras e transformadoras da ordem social, "conduzindo-as" para um determinado lugar pré-estabelecido.

Nesse sentido e de acordo com Foucault (2013), o termo "conduta" talvez seja um dos que melhor explique a especificidade das relações de poder, pois designa o ato de conduzir os outros, utilizando mecanismos de coerção mais ou menos delimitados, é, ao mesmo tempo, uma maneira de se comportar em um campo mais ou menos aberto de possibilidades. Podemos dizer que é o estabelecimento de relações de múltipla escolha com a vida. É claro que podemos escolher, mas reduzimos pela via de uma diversidade de regras institucionais a infinidade de possibilidades vitais a algumas poucas. Por isso parece ser tão importante a preservação de uma variedade mínima de escolhas: para alimentar o tal artifício do ideal de liberdade. Entendemos que essa é uma estratégia de uma forma de poder estatal.

Diante disso, cabe ressaltar que a centralização e a hierarquização do exercício de poder, tal como conhecemos hoje, são características da nossa forma de organização política materializada no formato Estado. Parece pró- 
prio da maioria das sociedades que se consideram como civilizadas uma forma de exercício de poder descolada das necessidades do grupo e garantida por uma espécie de constrangimento, na maioria das vezes, violento.

Outros universais também estão presentes nessas práticas e permeiam tanto a assistência de Estado - as políticas públicas - quanto às práticas filantrópicas - que não estão tão separadas daquelas: as boas intenções presentes na defesa dos direitos humanos. Como vimos, Coimbra, Lobo e Nascimento (2008) mostram-nos os princípios da negação e da falta, que supõem a possibilidade de salvação de vítimas, sustentando a proliferação de leis e as chamadas intervenções humanitárias. "Estas vêm se afirmando como mercadoria de consumo que se vende a bons preços no mercado capitalístico de direitos humanos" (COIMBRA; LOBO; NASCIMENTO, 2008, p. 96). Vemos, portanto, que são produzidos critérios para a pobreza ou a vítima - presas ao território da falta - sejam merecedoras das estratégias de assistência, mas, nesse mercado, é preciso produzir também a necessidade da salvação. E o que fazer com a recusa da salvação? Como pensar/intervir sobre os modos de subjetivação que escapam às formas hegemonicamente constituídas e que resistem à recondução? Eis o desafio do pastorado contemporâneo.

Foucault (2008) nos mostra que a figura desviante, como o delinquente, em relação a esse sujeito coletivo criado pelo contrato social, rasga esse contrato e cai do lado de fora desse sujeito coletivo. Aqui, também, nesse desenho que começa a esboçar a noção de população, ${ }^{9}$ vemos estabelecer-se uma divisória na qual o povo aparece como sendo, de uma maneira geral, aquele que resiste à regulação da população, que tenta escapar desse dispositivo pelo qual a população existe, se mantém, subsiste (e num nível ótimo). Podemos pensar na maneira como são tratadas as movimentações políticas atuais... Nas estratégias, por exemplo, de criminalização dos movimentos sociais... Tratam-se, não somente de maneiras de despotencializar movimentos de resistência, mas, também, de criar uma nova categoria de delinquência, ou ampliar antigas, emparelhando delinquência, desobediência e resistência.

\section{O Pastorado e as Contracondutas}

Como dissemos, nossas perguntas giram em torno, também, da possibilidade de inventar saídas, engendrando práticas psi menos pedagogizantes e docilizantes, oferecendo um contraponto à ideia de humano desenvolvida ao longo século XVIII, inspirando-se, por exemplo, na proposta espinosana de vida humana, em que o exercício de poder político jamais poderia se alinhar a uma espécie de representação, tampouco a ideia de cidadão devendo estar alicerçada em uma obediência subserviente à norma, à lei. Enfim, pensar na desconstrução das perspectivas do ingovernável como aquilo que deve ser eliminado das composições ditas humana.

\footnotetext{
${ }^{9}$ Apesar da importância da discussão da noção de população e sua relação com a noção de povo nesse trabalho de Foucault, não vamos desenvolvê-la aqui, pelo recorte necessário desse trabalho.
}

Pensemos, então, as possibilidades de colocar a questão das resistências no contexto do sistema pastoral. Uma inspiração para o nosso fazer cotidiano diz respeito à especificidade dessas "revoltas de conduta". Foucault (2008) destaca que elas são distintas das revoltas políticas contra o poder na medida em que ele se exerce sob a forma da soberania, distintas também na sua forma e no seu objetivo, na medida em que elas também servem à garantia da exploração. O que nos faz pensar nos pequenos ajustes que operamos cotidianamente e que funcionam com o objetivo de garantir a perpetuação do funcionamento de grandes máquinas burocráticas institucionais.

A própria invenção das práticas psi anexadas às instituições que a precedem podem ser pensadas como um grande ajuste. Um ajuste para garantir um governo melhor, mais competente. Do que nos serve pensar nesses ajustes? Talvez para fugir do automatismo; talvez para encontrar algum sentido em operar essas práticas; talvez para desistir de determinados espaços; talvez para inventar, para criar ou escapar. Como perceber a diferença entre um ajuste que mantém um funcionamento que interessa às máquinas capitalísticas e uma prática efetivamente transformadora, liberadora? Nesse sentido, Foucault (2008) destaca que as tais revoltas de condutas nunca são autônomas. As questões que as atravessam parecem estar sempre em torno de por quem se aceita ser conduzido, como se aceita ser conduzido e em direção a quê.

Como designar esse tipo de revoltas, ou antes, essa espécie de trama específica de resistência a formas de poder que não exercem a soberania e que não exploram, mas que conduzem? Empreguei frequentemente a expressão "revolta de conduta", mas devo dizer que ela não me satisfaz muito, porque a palavra "revolta" é ao mesmo tempo demasiado precisa e demasiado forte para designar certas formas de resistência muito mais difusas e muito mais suaves. [...] a palavra "desobediência" é, em compensação, uma palavra sem dúvida fraca demais, ainda que seja de fato o problema da obediência que está no centro de tudo isso (FOUCAULT, 2008, p. 264).

Também para nós é o problema da obediência que está no centro da instauração de algo como a governamentalidade e de determinados modos de produção de subjetividades sob a qual as práticas psi engajar-se-ão. Trata-se, ao mesmo tempo, de fortalecer moral e socialmente as condutas obedientes como aquilo que está mais próximo do que se considera humano e criar uma rede institucional que visa, entre outras coisas, complexificar os modos de exercício de poder, produzindo verdades que promovem a legitimação desses valores a partir das falas competentes. E é diante desses desdobramentos que estamos propondo pensar como se experimentam saídas, escapes.

Insatisfeito com as possibilidades de designar as maneiras de fazer frente ao exercício do poder pastoral, Foucault (2008) propõe, finalmente, e ainda reticente, a expressão "contraconduta", que precisa estar necessariamente articulada ao sentido da palavra "conduta". Define-a como luta contra os procedimentos postos em prática para conduzir os outros, acentuando o sentido ativo da palavra. Não se trata, pois, de uma possibilidade de encontrar uma saída como uma fuga que muito pro- 
vavelmente cairia no vazio, mas de uma ação contrária e que visa, portanto, despotencializar os vetores que atuam sobre a condução dos outros. Esse autor vai chamar de contracondutas, por exemplo, as lutas antipastorais que definem todo um novo contexto que envolve comportamento religioso, uma nova maneira de fazer e de ser, uma nova maneira de se relacionar com Deus, com suas obrigações, com a moral e com a vida civil também.

\section{Considerações Finais}

Finalmente, tentamos evidenciar as práticas psi pensadas em um contexto de uma economia de circulação dos discursos e dos jogos de verdade como uma atualização da prática pastoral, ${ }^{10}$ operando estratégias de ortopedia, de produção de obediência através de dispositivos que Foucault (2008) chamou de dependência integral, que fortalecem processos de individualização e despotencialização da vida como ação política. Será possível pensar micropoliticamente as práticas psi como não limitadas a aparar as possíveis arestas do processo de governamentalização do povo, engajando-se em processos de fortalecimento do ingovernável? De potencialização do que excede às delimitações das fronteiras entre normal e anormal, saúde e doença, o humano e o monstro?

Sabemos que a produção de subjetividade é efeito de uma multiplicidade de práticas, articulando campos de saberes e exercício de poderes de naturezas distintas, mas qual seria o campo imediatamente criado e convocado para operar o desejo? Quais tipos de especialistas seriam os mais "adequados" para acessar esse motor de ação do que o autor em questão chamaria de povo? Não estamos, portanto, colocando em análise as práticas psi, apenas porque nos situamos nelas, mas porque as consideramos como ocupando um lugar de poder estrategicamente importante no que diz respeito à produção de subjetividades governáveis.

Podemos pensar que o poder pastoral, através do governo por individualização, visa o enfraquecimento máximo do outro. Não a ponto de eliminá-lo, pois não haveria mais exercício de poder, mas a ponto de produzir uma dependência integral e, portanto, uma relação de obediência. Consideramos que o campo das supostas garantias de direito é um campo de luta, onde nada está garantido de antemão, por isso, pensamos como problemática a produção de submissão. Trata-se, portanto, de afirmar a importância da conservação do Direito de Guerra, inclusive, como modo sem qual não pode conceber a paz.

O sentido de paz mencionado aqui também precisa ser colocado em questão. Nos seus usos corriqueiros, entendemos que se busca a paz como se busca uma sensação de tranquilidade. No nível das relações sociais, como se busca um consenso, no nível mais individual ou, como preferimos, singularizado, busca-se, principalmente,

\footnotetext{
${ }^{10}$ Cabendo destacar que essa prática pastoral, como atividade de gestão política, passa a ser nomeada pelo filósofo francês como pastorado laico ou pastorado de Estado. Importante notar que a laicidade é uma condição sem a qual não se poder conceber o Estado, para esse autor. Entendemos que o contexto francês pode permitir essa condição... Mas não se aplicaria a nossa análise ou a nosso contexto. Portanto, damos ênfase ao que chamamos de pastorado contemporâneo como pastorado de Estado e só se pode considerá-lo laico no nível formal, burocrático, mas não no nível das práticas.
}

uma ausência de angústias ${ }^{11}$ ou dissonâncias. Pois bem, entendemos esses usos como processos de pacificação, em ambos os níveis como processos de produção de consenso e, portanto, de morte da vida política.

Uma cidade em que os súditos não pegam em armas pelo óbvio motivo de que o terror os paralisa, tudo que o que se pode dizer dela é que não tem guerra, mas não que tenha paz. Por que a paz não é ausência de guerra; é a virtude que nasce do vigor da alma... (pelo art. 19 do cap. II), é uma vontade constante de executar tudo o que deve ser feito conforme o decreto comum $^{12}$ da cidade. Afinal, uma cidade onde a paz não tem outra base que a inércia dos súditos, os quais se deixam conduzir como um gado e só são exercitados na escravidão, não é mais uma cidade, mas uma solidão (ESPINOSA apud BOVE, 2010, p. 154).

\section{Referências}

ABREU, A. M. R. M. de. O simulacro da clínica. 1991. Trabalho de Conclusão de Curso (especialização em Psicanálise). Faculdade de Psicologia, Universidade Santa Úrsula, Rio de Janeiro, 1991.

BOVE, L. Direito de guerra e direito comum na política espinosana. In: Espinosa e a Psicologia Social: ensaios de ontologia política e antropogênese. Belo Horizonte: Autêntica/Nupsi-USP, 2010. p. 153-164.

COIMBRA, C. M. B. Psicologia e Política: a produção de verdades competentes. 2002. Disponível em: <http://www. slab.uff.br/psm/uploads/texto67.pdf>. Acesso em: 1 jul. 2015.

COIMBRA, C. M. B.; LOBO, L.; NASCIMENTO, M. L. Por uma invenção ética para os Direitos Humanos. Psicol. clin., v. 20, n. 2, p. 89-102, 2008. Disponível em: <http:// www.scielo.br/pdf/pc/v20n2/a07v20n2.pdf>. Acesso em: 7 jul. 2015.

COIMBRA, C. M. B.; LOBO, L.; NASCIMENTO, M. L. A invenção do humano como modo de assujeitamento. In: MENDONÇA FILHO, M.; NOBRE, M. T. (Org.). Política e afetividade: narrativas e trajetórias de pesquisa. Salvador: EDUFBA; São Cristóvão: EDUFES, 2009. p. 31-42. Cross ${ }^{\text {Ref. }}$

ESPINOSA, B. Tratado Político. São Paulo: Martins Fontes, 2009.

FOUCAULT, M. Segurança, Território e População: curso dado no Collège de France (1977-1988). Tradução de Eduardo Brandão. São Paulo: Martins Fontes, 2008.

FOUCAULT, M. O Sujeito e o Poder. In: DREYFUS, H. L.; RABINOW, P. Uma Trajetória Filosófica: para além do estruturalismo e da hermenêutica. 2. ed. Rio de Janeiro: Forense Universitária, 2013. p. 231-249.

GROS, F. Le Principe Sécurité. Paris: Gallimard, 2012.

MENDONÇA FILHO, M. C. C. Violência institucional e função educativa no estado do capitalismo financeiro. In: NEVES, P. S. da C. (Org.). Educação e Cidadania: questões contemporâneas. São Paulo: Cortez, 2009. v. 1, p. 60-91.

\footnotetext{
${ }^{11}$ Talvez aqui resida uma forte razão da predominância da lógica da medicalização no cuidado com a saúde, para sucesso das indústrias farmacêuticas e para o avanço de uma ordem médica focada no esquadrinhamento de doenças, perseguição e aniquilamento dos sintomas, além, é claro da própria rentabilidade implicada no processo de produção e venda dessas supostas soluções rápidas. ${ }^{12}$ Grifo nosso.
} 
VEYNE, P. Foucault revoluciona a História. In: . Como se escreve a História. 4. ed. Brasília: Universidade de Brasília (UNB), 1998. p. 239-285.

Recebido em: 9 de abril de 2015 Aceito em: 15 de setembro de 2017 